\title{
Total glucosides of paeony ameliorates TNBS-induced colitis by modulating differentiation of Th17/Treg cells and the secretion of cytokines
}

\author{
HAIHUA LIN ${ }^{1}$, WENYOU ZHANG $^{1}$, XUEPEI JIANG $^{1}$, RENPIN CHEN $^{1}$, XIELIN HUANG $^{2}$ and $^{\text {ZHIMING HUANG }}{ }^{1}$ \\ ${ }^{1}$ Department of Gastroenterology, The First Affiliated Hospital of Wenzhou Medical University; \\ ${ }^{2}$ Department of Clinical Medicine, Renji College of Wenzhou Medical University, Wenzhou, Zhejiang 325035, P.R. China
}

Received August 25, 2016; Accepted June 20, 2017

DOI: $10.3892 / \mathrm{mmr} .2017 .7598$

\begin{abstract}
The imbalance between effector $\mathrm{CD}^{+} \mathrm{T}$ helper 17 (Th17) and regulatory $\mathrm{CD} 4^{+} \mathrm{T}$ cells (Treg) cells and their associated cytokines, have been associated with the pathogenesis of inflammatory bowel disease (IBD). Total glycosides of paeony (TGP) is an alternative immunomodulatory agent that is widely used for the treatment of autoimmune diseases. The present study aimed to evaluate the modulatory effect of TGP in a rat model of colitis induced by 2,4,6-trinitrobenzene sulfonic acid (TNBS). TGP was administered intragastrically $24 \mathrm{~h}$ after the TNBS intrarectal instillation for 7 days. TGP treatment ameliorated the clinical status and reversed the histopathologic severity of acute TNBS colitis. Furthermore, TGP inhibited the levels of Th17-associated cytokines interleukin (IL)-17, IL-6, tumor necrosis factor- $\alpha$, whereas the expression levels of Treg-associated cytokines IL-10, transforming growth factor- $\beta$ in the plasma, colon, spleen and mesenteric lymph nodes (MLN). Additionally, TGP reduced
\end{abstract}

Correspondence to: Professor Zhiming Huang, Department of Gastroenterology, The First Affiliated Hospital of Wenzhou Medical University, Building 1, South Baixiang Street, Shangcai Village, Ouhai, Wenzhou, Zhejiang 325035, P.R. China

E-mail: wzhospitalhzm@126.com

Abbreviations: IBD, inflammatory bowel disease; Treg, regulatory $\mathrm{CD}^{+} \mathrm{T}$ cells; IL-17, interleukin-17; Th17, effector $\mathrm{CD}^{+} \mathrm{T}$ helper 17; TNBS, trinitrobenzene sulfonic acid; $\mathrm{CD}$, Crohn's disease; UC, ulcerative colitis; TNF- $\alpha$, tumor necrosis factor- $\alpha$; PVDF, polyvinylidene fluoride; PF, paloniflorin; Foxp3, forkhead boxp3; TGP, total glycosides of paeony; RA, rheumatoid arthritis; SLE, systemic lupus erythematosus; AS, ankylosing spondylitis; T-bet, T-box expressed in T cells; SD, Sprague-Dawley; SASP, sulfasalazine; MLN, mesenteric lymph nodes; TNF- $\beta$, transforming growth factor- $\beta$; GAPDH, glyceraldehyde-3-phosphate dehydrogenase; ROR- $\gamma \mathrm{t}$, retinoic acid related orphan receptor- $\gamma \mathrm{t}$; ELISA, enzyme-linked immunosorbent assay; PMA, phorbol 12-myristate 13-acetate

Key words: total glucosides of paeony, inflammatory bowel disease, regulatory T cells, Th17 effector cells the percentage of Th17 cells; however, the proportion of Treg cells in the spleen and MLN was increased. The present study also observed a suppression of Th17-associated transcription factor, termed retinoid-related orphan receptor- $\gamma \mathrm{t}(\mathrm{ROR}-\gamma \mathrm{t})$. However, expression of the Treg-associated transcription factor forkhead boxp3 was increased in the TGP treatment group. Therefore, the present findings suggest that TGP has a regulatory role in modulating the balance of Th17 and Treg cells to ameliorate the TNBS-induced colitis and support the strategy of using TGP to treat IBD.

\section{Introduction}

Inflammatory bowel disease (IBD), encompassing Crohn's disease (CD) and ulcerative colitis (UC), is an inflammatory disorder affecting the gastrointestinal tract. Clinical symptoms include abdominal pain, diarrhea, rectal bleeding, anemia, fatigue and malnutrition, all conditions associated with reduced in quality of life (1-3). Although the exact etiology is complex and remains to be elucidated, the available evidence suggests that various factors, such as heredity, defective epithelial barrier, increased intestinal permeability, antimicrobial peptide production, innate microbial sensing and autophagy may be involved in pathogenesis of $\operatorname{IBD}(2,4)$. In particular, an excess of inflammatory mediators and an inadequate function or number of components that downregulate mucosal immune response may have an important role in $\operatorname{IBD}(5,6)$. The normal intestinal immune system has two tasks: To combat pathogens and to maintain tolerance towards the commensal bacterial flora $(2,5,7,8)$. However, not achieving these tasks leads to the pathological inflammation of the gut system.

There are various inflammatory cells in the gut and along with Thelper (Th) 1 and Th 2 cells, effector $\mathrm{CD}^{+}{ }^{+} \mathrm{T}$ helper 17 (Th17) and regulatory $\mathrm{CD}^{+} \mathrm{T}$ cells (Treg) are also important in IBD. The loss of homeostasis between Th17 and Treg cells is believed to lead to an aberrant immune response of IBD $(1,5,9)$. Th17 cells have a critical role in clarifying extracellular pathogens, the inappropriate expression of pro-inflammatory cytokines by those cells, such as interleukin (IL)-17A, IL-17F, IL-21, IL-22, is believed to favor the occurrence of inflammatory diseases $(9,10)$. Previous studies have revealed an increased number of Th17 cells expressing retinoid-related orphan receptor- $\gamma \mathrm{t}(\mathrm{ROR}-\gamma \mathrm{t})$, 
the master transcription factor guiding Th17 differentiation, in the lamina propria of IBD patients, which suggests that Th17 cells may contribute to the pathology of IBD (11-13). Th17 cells facilitate intestinal inflammation in both forms of IBD; however, Treg cells have anti-inflammatory properties (7). Treg cells are necessary for the maintenance of mucosal tolerance and preserve homeostasis in the gut by suppressing the proliferation and effector functions of effector T cells (9). Treg cells exhibit their anti-inflammatory function by producing the effective cytokines, such as IL-10 and transforming growth factor- $\beta$ (TNF- $\beta$ ) $(2,14)$. The transcription factor forkhead box p3 (Foxp3), which is crucial for their differentiation and function, has been confirmed to be expressed in intestinal mucosa in order to inhibit abnormal immune responses toward the dietary antigens or commensal flora. Previous studies have determined that Treg cells are involved in the anti-inflammatory action in IBD patients (9,14-16). Additionally, there is evidence that Treg cells are capable of controlling experimental colitis in animal models $(17,18)$.

Th17 and Treg cells may control the development of one another to maintain immune homeostasis and achieve pathogen clearance. TNF- $\beta$ has been identified as an anti-inflammatory cytokine produced by Treg cells and the critical common factor for the proliferation of Th17 and Treg cells $(19,20)$. It has been previously reported that TNF- $\beta$ promotes the differentiation of Treg cells by inducing Foxp3 expression, whereas it favors the differentiation of Th17 cells in the concurrent administration of IL-6 and TNF- $\beta$ (21-24).

Total glucosides of paeony (TGP), extracted from the root of Paeonia lactiflora Pall., contains $96.2 \%$ of paloniflorin (PF) and traces of hydroxyl-paconiflorin, abbiflorin, paeonin, benzoylpaeoniflorin (25). According to the dispensatory of TGP, paeoniflorin is the monomer which has an effective role and accounts for $90 \%$ of TGP. As a traditional Chinese herbal medicine, TGP has been identified to exhibit a wide range of pharmacological activities, including anti-inflammatory, antioxidative, antihepatic, analgesic activity without evident toxic or side effects (26-30). TGP has been used for dysmenorrhea, muscle cramping and spasms, giddiness and fever in China for over 1,500 years. TGP was approved to enter the Chinese market in 1998, and has been used for the treatment of rheumatoid arthritis (RA), systemic lupus erythematosus (SLE), ankylosing spondylitis (AS) and hepatitis $(31,32)$. Previous studies revealed that TGP may inhibit Th1/Th17 immune response by downregulating the expression of transcriptional factor T-box expressed in T cells (T-bet) and RORgt. Meanwhile, TGP may increase the $\mathrm{CD} 4{ }^{+} \mathrm{CD} 25^{+}$Treg differentiation by activating the transcription factor Foxp3 (30,33-36). A previous study revealed that TGP effectively attenuated inflammation in 2,4,6-trinitrobezence sulfonic acid (TNBS)/ethanol-induced colitis in rats (37). This evidence supported the hypothesis that TGP may be a promising candidate Chinese drug for treatment of IBD. However, whether TGP reduces inflammation of IBD via regulating Th17/Treg balance remains to be elucidated. Therefore, the present study measured the expression of Th17 and Treg-associated cytokines and transcription factors, and the proportion of Th17 and Treg cells in the TNBS-induced colitis model. The purpose of the present study was to further elucidate the regulatory effects and underlying mechanism of TGP in a rat model of TNBS-induced colitis via Th17/Treg immune homeostasis.

\section{Materials and methods}

Animals. A total of 32 Sprague-Dawley (SD) rats (male, 6-8-weeks old, mean weight, $200 \mathrm{~g}$ ) were purchased from Shanghai SLAC Laboratory Animal Co., Ltd. (Shanghai, China). Animals were kept in standard cages (5 rats/cage) under specific pathogen-free conditions in the Laboratory Animal Research Center of Wenzhou Medical University. Rats were given free access to autoclaved tap water and to a standard diet, maintained under controlled conditions of light (12-h light-dark cycle), temperature $\left(22-24^{\circ} \mathrm{C}\right)$ and humidity $(45-55 \%)$. All procedures were ethically approved according to the Guide for the Care and Use of the Administration Committee of Experimental Animals of Wenzhou Medical University (Wenzhou, China).

Ethical considerations. In accordance with the Association for the Assessment and Accreditation of Laboratory Animal Care International, rats were maintained under specific pathogen-free conditions and studied according to protocols approved by the Wenzhou Medical University Animal Care and Use Committee (approval no. wydw2013-0071).

Induction of experimental colitis in rats. Rats were weighed and anesthetized by intraperitoneal injection of ketamine/xylazine solution ( $80 \mathrm{ml} / 10 \mathrm{~g}$ body weight). TNBS (Sigma-Aldrich; Merck Millipore, Darmstadt, Germany) was dissolved in alcohol (50:50 vol/vol). TNBS solution $(100 \mathrm{mg} / \mathrm{kg}$ body weight) was administered intrarectally via $3.5 \mathrm{~F}$-catheter to rats maintained for $60 \mathrm{sec}$ in a vertical position. The catheter was inserted into the colon $8 \mathrm{~cm}$ proximal to the anus. The normal control group received $0.9 \%$ saline intrarectally (38).

Treatment with TGP. SD rats were randomly assigned to four groups ( $\mathrm{n}=8 /$ group): Normal control group, TNBS-treated group, sulfasalazine (SASP)-treated group and TGP-treated group. SASP (Shanghai Sunve Pharmaceutical Co., Ltd., Shanghai, China) and TGP (Ningbo Liwah Pharmaceutical Co., Ltd., Ningbo, China) were respectively administered at the doses of $100 \mathrm{mg} / \mathrm{kg} /$ day in the SASP-treated and TGP-treated group by gastric gavage daily from day 1 ( $24 \mathrm{~h}$ after the induction of colitis) for 7 days prior sacrifice. Normal control group and TNBS-treated group were treated with an equal volume of $0.9 \%$ saline alone intragastrically.

Clinical analysis of colitis. The clinical progression of colitis was monitored daily for body weight, diarrhea and hemafecia (3). Loss of body weight was calculated as the percentage difference relative to initial body weight. Diarrhea was scored as follows: 0 , Normal; 2, loose stools; and 4, diarrhea that remained adhesive to the anus. Bleeding scores were assessed as follows: 0, Negative hemoccult; 2, positive hemoccult; and 4, obvious bleeding (39).

Assessment of colonic damage. Rats were sacrificed 7 days after drug treatment. The colon was removed and opened longitudinally. The macroscopic damage was measured by a blinded observer with the following score system $(40,41)$ : 0 , Normal; 1 , hyperemia, edema, no ulcer; 2 , hyperemia, edema, small linear ulcers or petechiae; 3 , hyperemia, edema, wide ulcers, necrosis, or adhesions; 4, hyperemia, edema, megacolon, stenosis, or perforation. For histological analysis, the colonic fragments $(0.5 \mathrm{~cm})$ 
Table I. Primers used for quantitative polymerase chain reaction.

\begin{tabular}{lll}
\hline Gene & \multicolumn{1}{c}{ Sense $\left(5^{\prime}-3^{\prime}\right)$} & \multicolumn{1}{c}{ Antisense $\left(5^{\prime}-3^{\prime}\right)$} \\
\hline GAPDH & GACATGCCGCCTGGAGAAAC & AGCCCAGGATGCCCTTTAGT \\
IL-17 & TACAGTGAAGGCAGCGGTA & GCTAAGGGAGTTGAGGACTTTC \\
IL-6 & TGCCTTCCCTACTTCACA & ACAACTCTTTTCTCATTTCCA \\
TNF- $\alpha$ & GTCGTAGCAAACCACCAAGC & GAAGAGAACCTGGGAGTAGATAAGG \\
ROR- $\gamma \mathrm{t}$ & AGGCAAATACGGTGGTGTGG & ATTGCAGATGCTCCACTCTCC \\
TGF- $\beta$ & ATTCCTGGCGTTACCTTG & CCCTGTATTCCGTCTCCT \\
IL-10 & GGAGTGAAGACCAGCAAA & GCAACCCAAGTAACCCTT \\
Foxp3 & CCATAATATGCGGCCCCCTT & GCGGGGTGGTTTCTGAAGTA
\end{tabular}

GAPDH, glyceraldehyde-3-phosphate dehydrogenase; IL, interleukin; TNF- $\alpha$, tumor necrosis factor- $\alpha$; ROR- $\gamma$ t, retinoic acid related orphan receptor- $\gamma \mathrm{t}$; TGF- $\beta$, transforming growth factor- $\beta$; Foxp3, forkhead boxp3.

were fixed in $4 \%$ paraformaldehyde, dehydrated, embedded in paraffin, sectioned ( $4 \mu \mathrm{m}$ thickness) and stained with $10 \%$ hematoxylin for $2 \mathrm{~min}$ and $0.5 \%$ eosin for $1 \mathrm{~min}$ at room temperature. The pathological sections were observed under a light microscope by two blinded pathologists and the microscopic damage was scored as follows (42): 0, No evidence of inflammation; 1 , low level of inflammation with scattered infiltrating mononuclear cells (1-2 foci); 2, moderate inflammation with multiple foci; 3 , high level of inflammation with increased vascular density and marked wall thickening; 4, maximal severity of inflammation with transmural leukocyte infiltration and loss of goblet cells.

Immunohistochemistry. The colon specimens were fixed with $4 \%$ paraformaldehyde, embedded with paraffin, and sectioned at $4 \mu \mathrm{m}$ for immunohistochemical staining for IL-17, IL-6, ROR- $\gamma \mathrm{t}$, tumor necrosis factor- $\alpha$ (TNF- $\alpha$ ), IL-10, TNF- $\beta$ and Foxp3. After incubation with xylene and descending concentrations of ethanol, antigens were retrieved by citrate buffer for $15 \mathrm{~min}$ at $100^{\circ} \mathrm{C}$. Then endogenous peroxidases were removed in $3 \%$ hydrogen peroxidase for $15 \mathrm{~min}$ at room temperature followed by $5 \%$ goat serum for $1 \mathrm{~h}$ at $37^{\circ} \mathrm{C}$ for blocking. Subsequently, sections were incubated with polyclonal rabbit anti-rat antibodies IL-17 (cat. no. ab79056; 1:300), ROR- $\gamma$ t (cat. no. ab78007; 1:50), TNF- $\alpha$ (cat. no. ab6671; 1:250), IL-10 (cat. no. ab192271; $1: 1,000)$, TNF- $\beta$ (cat. no. ab92486; 1:100) and monoclonal mouse anti-rat IL-6 (cat. no. ab9324; 1:250), Foxp3 (cat. no. ab22510; 1:50; Abcam, Cambridge, MA, USA) in an optimum concentration overnight at $4^{\circ} \mathrm{C}$ and then incubated with horseradish peroxidase-conjugated secondary antibody (cat. nos. PV.6001 and PV.6002; OriGene Technologies, Inc., Beijing, China) for $30 \mathrm{~min}$ at $37^{\circ} \mathrm{C}$. Antibody bindings were counterstained with hematoxylin, dehydrated with ascending concentrations of ethanol, cleared in xylene and mounted. A negative control was performed according to the same procedure. Images were acquired with a biological imaging microscope (BX53; Olympus Corporation, Tokyo, Japan).

Western blot analysis. Total protein of colon specimens was extracted using a radioimmunoprecipitation lysis buffer (Solarbio Science \& Technology Co., Ltd., Beijing, China) and phenylmethylsulfonyl fluoride. The protein concentration was analyzed using a BCA kit (Tiangen Biotech Co., Ltd., Beijing, China). Equal amounts of protein (50 $\mu \mathrm{g}$ per lane) were separated on $12 \%$ SDS-polyacrylamide gels and transferred onto polyvinylidene fluoride (PVDF) membrane (EMD Millipore, Bedford, MA, USA). After blocking with 5\% non-fat milk for $90 \mathrm{~min}$ at room temperature, the membranes were incubated overnight at $4^{\circ} \mathrm{C}$ with anti-IL-17 (cat. no. ab79056; polyclonal, rabbit anti-rat; 1:1,000), anti-IL-6 (cat. no. ab9324; monoclonal, mouse anti-rat; 1:2,500), anti-ROR- $\gamma$ t (cat. no. ab78007; polyclonal, rabbit anti-rat; 1:1,000), anti-TNF- $\alpha$ (cat. no. ab6671; polyclonal, rabbit anti-rat; 1:1,000), anti-IL-10 (cat. no. ab192271; polyclonal, rabbit anti-rat; $1: 1,000$ ), anti-TNF- $\beta$ (cat. no. ab92486; polyclonal, rabbit anti-rat; 1:1,000) and anti-Foxp3 (cat. no. ab22510; monoclonal, mouse anti-rat; 1:1,000; all from Abcam, Cambridge, MA, USA) and anti-glyceraldehyde-3-phosphate dehydrogenase (GAPDH; cat. no. BS60630; polyclonal, rabbit anti-rat; 1:1,000; Bioworld Technology, Inc., St. Louis Park, MN, USA) and washed three times with TBST. Then the membranes were incubated with secondary antibodies-conjugated to horseradish peroxidase (cat. no. 7074; 1:5,000; Cell Signaling Technology, Inc., Danvers, MA, USA) for $1 \mathrm{~h}$ at room temperature followed by washing three times. Immunoreactive bands were visualized by an enhanced chemiluminescence kit (Bio-Rad Laboratories, Hercules, CA, USA).

Reverse transcription-quantitative polymerase chain reaction $(R T-q P C R)$. Total RNA was extracted from the colon tissue, spleen mononuclear cells and mesenteric lymph node (MLN) mononuclear cells using TRIzol (Invitrogen; Thermo Fisher Scientific, Inc., Waltham, MA, USA) according to the manufacturer's protocol. RNA ( $1 \mu \mathrm{g}$ total) was reverse-transcribed into cDNA. Reverse transcription was carried out by RevertAid First Strand cDNA Synthesis kit (cat. no. K1622; Thermo Scientific Inc.). The temperature conditions for the reverse transcription were as follows: Initial cycle at $25^{\circ} \mathrm{C}$ for $5 \mathrm{~min}$, followed by $42^{\circ} \mathrm{C}$ for $60 \mathrm{~min}$ and $72^{\circ} \mathrm{C}$ for $10 \mathrm{~min}$, allowed to cool to $4^{\circ} \mathrm{C}$. The mRNA expression of several genes was quantified with SYBR-Green Real-time PCR Master Mix Plus (Thermo Fisher Scientific, Inc.) by an ABI 7500 Sequence-Detection system (Thermo Fisher Scientific, Inc.). The PCR cycling conditions were as follows: An initial denaturation and activation at $95^{\circ} \mathrm{C}$ for $10 \mathrm{~min}$, followed by 40 amplification cycles of $95^{\circ} \mathrm{C}$ for $15 \mathrm{sec}$ and $60^{\circ} \mathrm{C}$ for $60 \mathrm{sec}$. The primer sequences are presented in Table I. GAPDH was 
used as reference gene. Relative gene expression levels were calculated by the $2^{-\Delta \Delta \mathrm{Cq}}$ method (43).

Enzyme-linked immunosorbent assay (ELISA) analysis. Peripheral blood of rats was drawn into EDTA-anticoagulant tubes, then centrifuged for $15 \mathrm{~min}$ at $3,000 \mathrm{x} \mathrm{g}$ at $4^{\circ} \mathrm{C}$. The plasma was collected and stored at $-80^{\circ} \mathrm{C}$ until tested. ELISA kits were used to assess the plasma concentrations of IL-17 (cat. no. 10353-09R), IL-6 (cat. no. 10752-09R), TNF- $\alpha$ (cat. no. 10917-09R), IL-10 (cat. no. 10726-09R) and TNF- $\beta$ (cat. no. 10973-09R; all from Shanghai Boyun Biotech Co., Ltd., Shanghai China) in accordance with the manufacturer's protocols.

Flow cytometry analysis. The spleen and MLN were removed from rats 7 days after drug treatment and isolated mononuclear cells. In order to analyze Th17 cells, cells were stimulated with phorbol 12-myristate 13 -acetate (PMA) $(50 \mathrm{ng} / \mathrm{ml})$ and ionomycin $(1 \mu \mathrm{g} / \mathrm{ml})$ in the presence of Brefeldin A $(10 \mu \mathrm{g} / \mathrm{ml})$ and monensin $(1.4 \mu \mathrm{g} / \mathrm{ml})$ (Hangzhou MultiSciences Biotech Co., Ltd., Hangzhou China) at $37^{\circ} \mathrm{C}$ and $5 \% \mathrm{CO}_{2}$ for $4 \mathrm{~h}$. Cells were washed with PBS and surface-labeled with fluorescein isothiocyanate-(FITC-) conjugated anti-CD4 (0.5\%; cat. no. 85-11-0041-81; eBioscience; Thermo Fisher Scientific, Inc.) for $40 \mathrm{~min}$ at $4^{\circ} \mathrm{C}$. The cells were subsequently fixed and permeabilized by fixation/permeabilization buffer (BD Biosciences, San Jose, CA, USA) and labeled with phycoerythrin-(PE-) conjugated anti-IL-17 (1\%; cat. no. 85-12-7177-81; eBioscience; Thermo Fisher Scientific, Inc.) for $40 \mathrm{~min}$ at $4^{\circ} \mathrm{C}$. For analysis of Treg cells, without PMA and ionomycin stimulation, surface staining was performed with FITC-conjugated anti-CD4 (0.5\%; cat. no. 85-11-0041-81; eBioscience; Thermo Fisher Scientific, Inc.) and allophycocyanin-conjugated anti-CD25 (1.5\%; cat. no. 85-17-0390-82; eBioscience; Thermo Fisher Scientific, Inc.) for $40 \mathrm{~min}$ at $4^{\circ} \mathrm{C}$. Afterwards, cells were fixed and permeabilized, and intracellular staining was performed with PE-conjugated anti-Foxp3 (1.25\%; cat. no. 85-12-5773-82; eBioscience; Thermo Fisher Scientific, Inc.) for $40 \mathrm{~min}$ at $4^{\circ} \mathrm{C}$. Appropriate isotype controls were used in the experiments. The stained cells were detected by a FACSCalibur flow cytometer (BD Biosciences) and the data were analyzed with FlowJo version 7.6.1 (FlowJo LLC, Ashland, OR, USA).

Statistical analysis. Statistical analysis was performed using SPSS version 16.0 (SPSS, Inc., Chicago, IL, USA). Data are presented as mean \pm standard error and one-way analysis of variance was used for multiple comparisons, followed by Dunnett's post hoc test. $\mathrm{P}<0.05$ was considered to indicate a statistically significant difference.

\section{Results}

TGP ameliorates acute inflammatory of TNBS-induced colitis in rats. To evaluate the potential therapeutic effect of TGP in the TNBS-induced colitis, the present study tested the clinical symptoms and macroscopic scores in the aforementioned groups. As expected, the rats acquired severe symptoms characterized by weight loss, diarrhea and bleeding following TNBS instillation compared with the normal control group.
However, TGP and SASP treatment rapidly reversed weight loss and decreased bleeding and diarrhea scores compared with the TNBS group (Fig. 1A-C). The present study observed marked macroscopic change accompanied by hyperemia, edema, ulcers, necrosis and adhesion in TNBS-induced group, whereas the colons from TGP or SASP group exhibited no or a slight macroscopic damage (Fig. 1D). Consistently, the macroscopic scores of TNBS-induced rats were significantly increased compared with the control group and the TGP and SASP-treated groups (Fig. 1E). Histopathologically, the colonic tissues of TNBS-induced rats exhibited a reduced number of goblet cells, loss of crypts, damage of crypts, infiltration by inflammatory cells and extensive destruction of the mucosal layer compared with the control group (Fig. 2A). However, histological signs of inflammatory activity were distinctly reduced following TGP administration in TNBS-rats, similar to the SASP-treated group (Fig. 2). Therefore, treatment of TGP is effective in modulating the development of acute TNBS-induced colitis and the efficacy of TGP was similar to SASP.

TGP regulates the production of Th17- and Treg-associated cytokines and transcription factors in plasma and colonic tissues of TNBS-induced colitis model. In order to investigate the effects of TGP on acute inflammation, plasma and colonic tissue samples were collected at 7 days and the production of signature cytokines and transcription factors was measured by ELISA, western blotting and immunohistochemistry. The current results revealed that Th17-associated pro-inflammatory cytokines and transcription factors in colonic tissues of TNBS-induced rats, such as IL-17, IL-6, TNF- $\alpha$ and ROR- $\gamma$ t, were significantly reduced following administration of TGP and SASP treatment (Figs. 3 and 4). The TGP and SASP-treated groups also had higher levels of IL-10, TNF- $\beta$ and Foxp3 in colonic tissues compared with the untreated TNBS and control groups (Figs. 3 and 4). Similarly, TGP administration downregulated the expression of IL-17, TNF- $\alpha$, IL- 6 and upregulated the level of IL-10 and TNF- $\beta$ in plasma of TNBS-induced rats (Fig. 5). These findings indicate that TGP inhibits Th17 responses; however, may promote Treg responses in TNBS-induced colitis and there was no significant difference between treatment with TGP or SASP.

TGP modulates the mRNA levels of Th17- and Treg-associated cytokines and transcription factors in the TNBS-induced colitis. To determine whether TGP may adjust the mRNA expression of transcription factors and cytokines in Th17 and Treg cells, we tested the expression levels using RT-qPCR. TGP administration in TNBS-rats led to lower mRNA expression levels of TNF- $\alpha$, IL-6, IL-17 and ROR- $\gamma$ t in the colonic tissues, MLN and splenic lymphocytes (Figs. 6A-D, 7A-D and 8A-D). In contrast, the mRNA expression of IL-10, TNF- $\beta$ and Foxp3 increased in TNBS-rats treated with TGP (Figs. 6E-G, 7E-G and $8 \mathrm{E}-\mathrm{G})$.

TGP affects the differentiation of Th17 and Treg cells in the TNBS-induced colitis. Previous studies have revealed that Th17 and Treg cells play a distinct role in the control and development of IBD and the balance between Th17 and Treg cells proliferation levels is a critical factor in designing therapies 
A

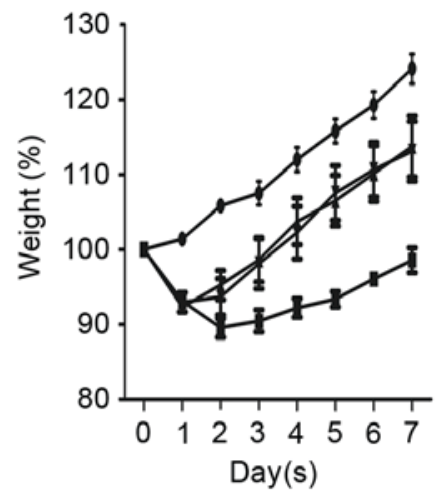

D
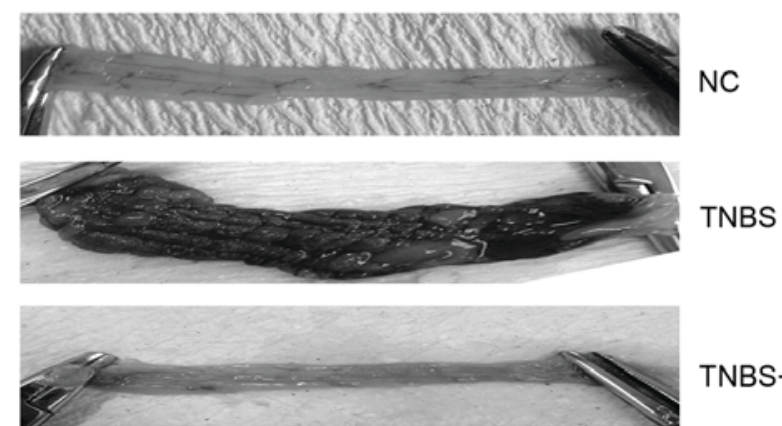

TNBS+SASP

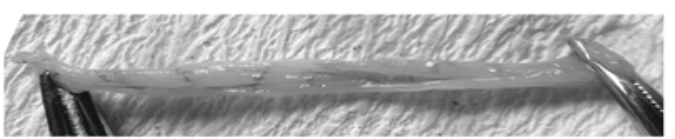

C

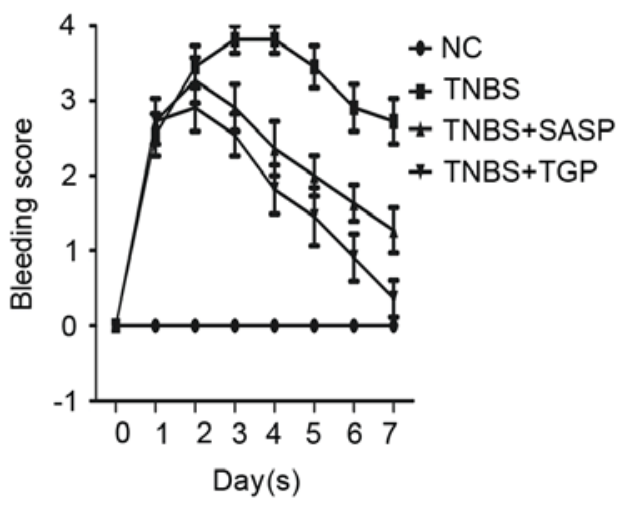

$E$

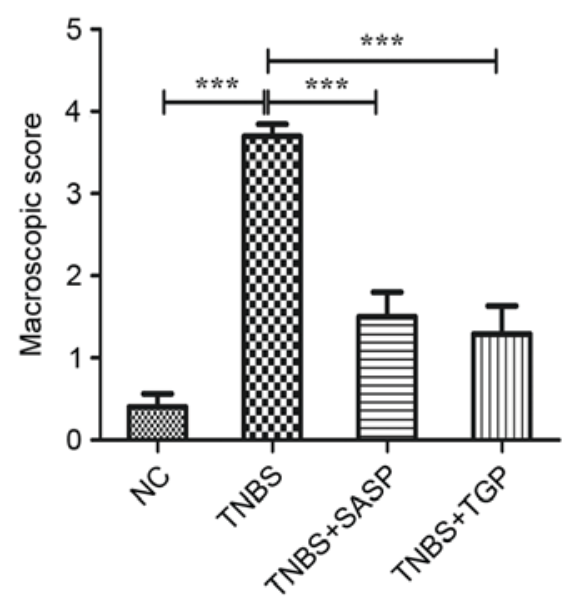

Figure 1. TGP improves the symptoms of TNBS-induced colitis and repairs colonic damage in a similar manner to SASP. Colitis was induced by intrarectal administration of $100 \mathrm{mg} / \mathrm{kg}$ TNBS with ethanol. Rats with TNBS-induced colitis were treated with $100 \mathrm{mg} / \mathrm{kg}$ TGP or $100 \mathrm{mg} / \mathrm{kg}$ SASP for 7 days. (A) Body weight change (percentage of original body weight), (B) diarrhea and (C) bleeding were scored daily. (D) Macroscopic observation and (E) macroscopic score were determined on day $7 .{ }^{* * *} \mathrm{P}<0.001, \mathrm{n} \geq 6$ per group. $\mathrm{NC}$, normal control group; TGP, total glycosides of paeony; SASP, sulfasalazine; TNBS, trinitrobenzene sulfonic acid-induced group; TNBS+SASP, TNBS-induced rats treated with SASP; TNBS+TGP, TNBS-induced rats treated with TGP.

A

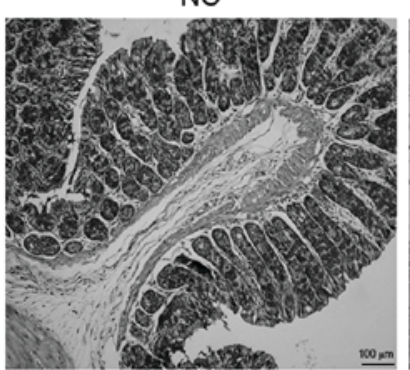

TNBS+SASP

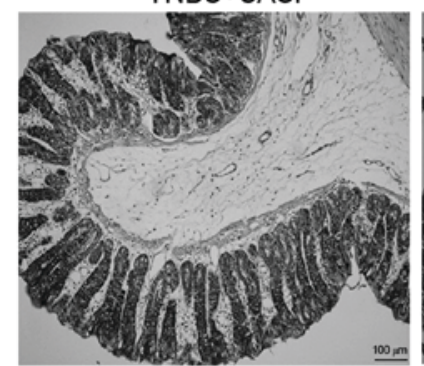

TNBS

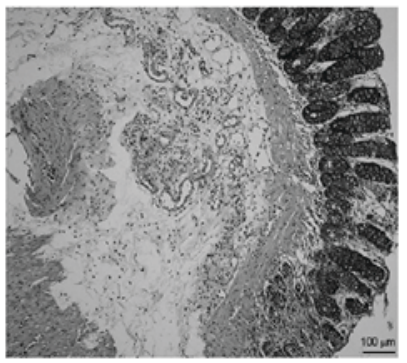

TNBS+TGP

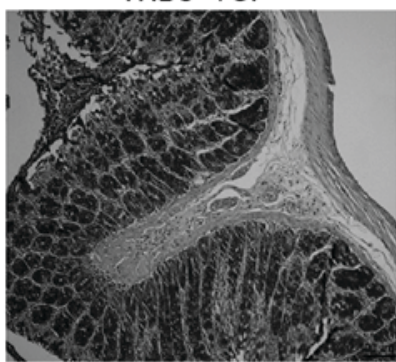

B

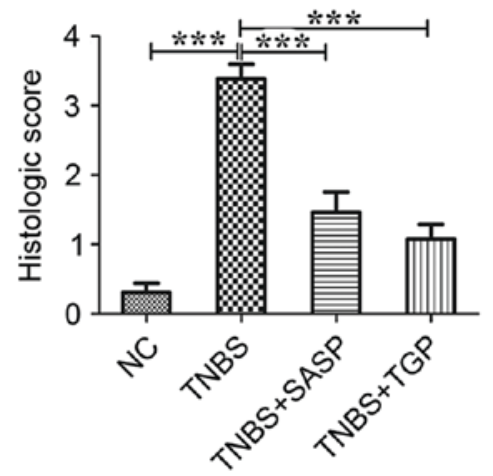

Figure 2. TGP alleviates histological signs of inflammatory in TNBS-induced colitis equal to SASP. (A) Representative H\&E-stained colon sections were performed 7 days after TGP or SASP treatment. Magnification, $\mathrm{x} 100$. (B) Histological score was calculated. ${ }^{* * *} \mathrm{P}<0.001$, $\mathrm{n} \geq 6$ per group. NC, normal control group; TGP, total glycosides of paeony; SASP, sulfasalazine; TNBS, trinitrobenzene sulfonic acid-induced group; TNBS+SASP, TNBS-induced rats treated with SASP; TNBS+TGP, TNBS-induced rats treated with TGP. 
A

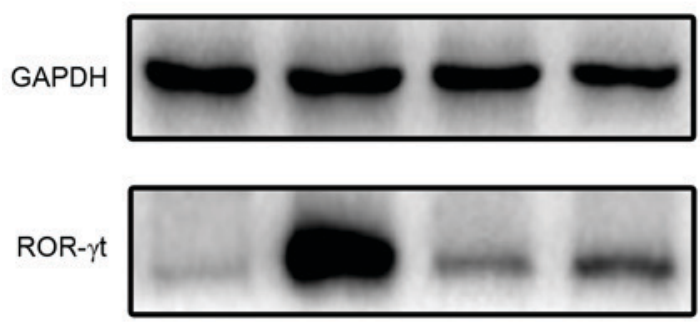

IL-17

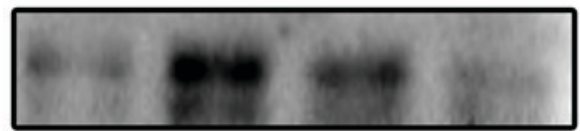

IL-6
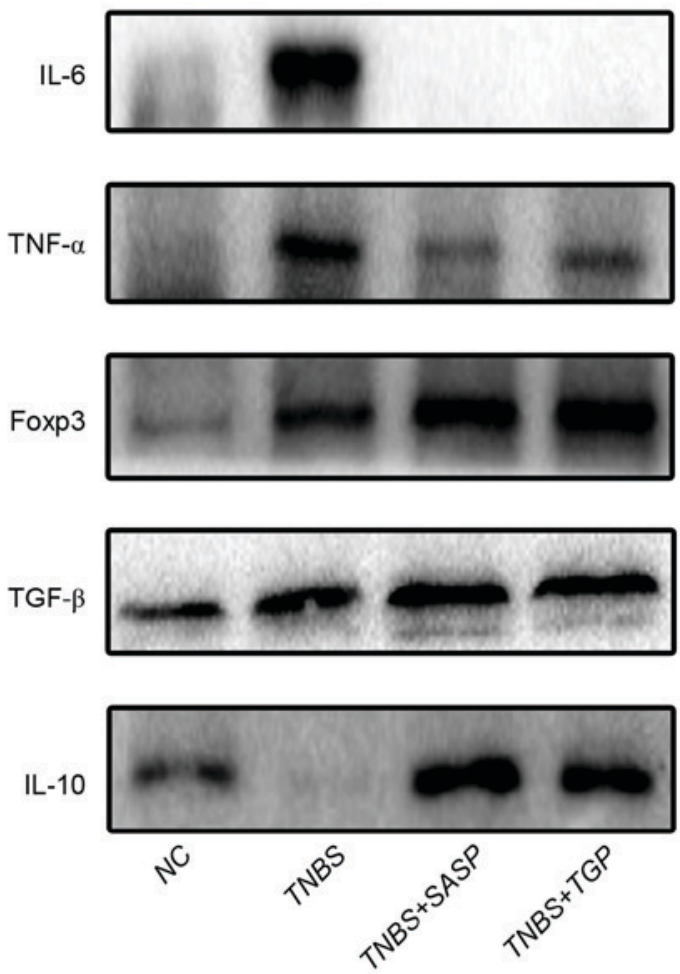

B
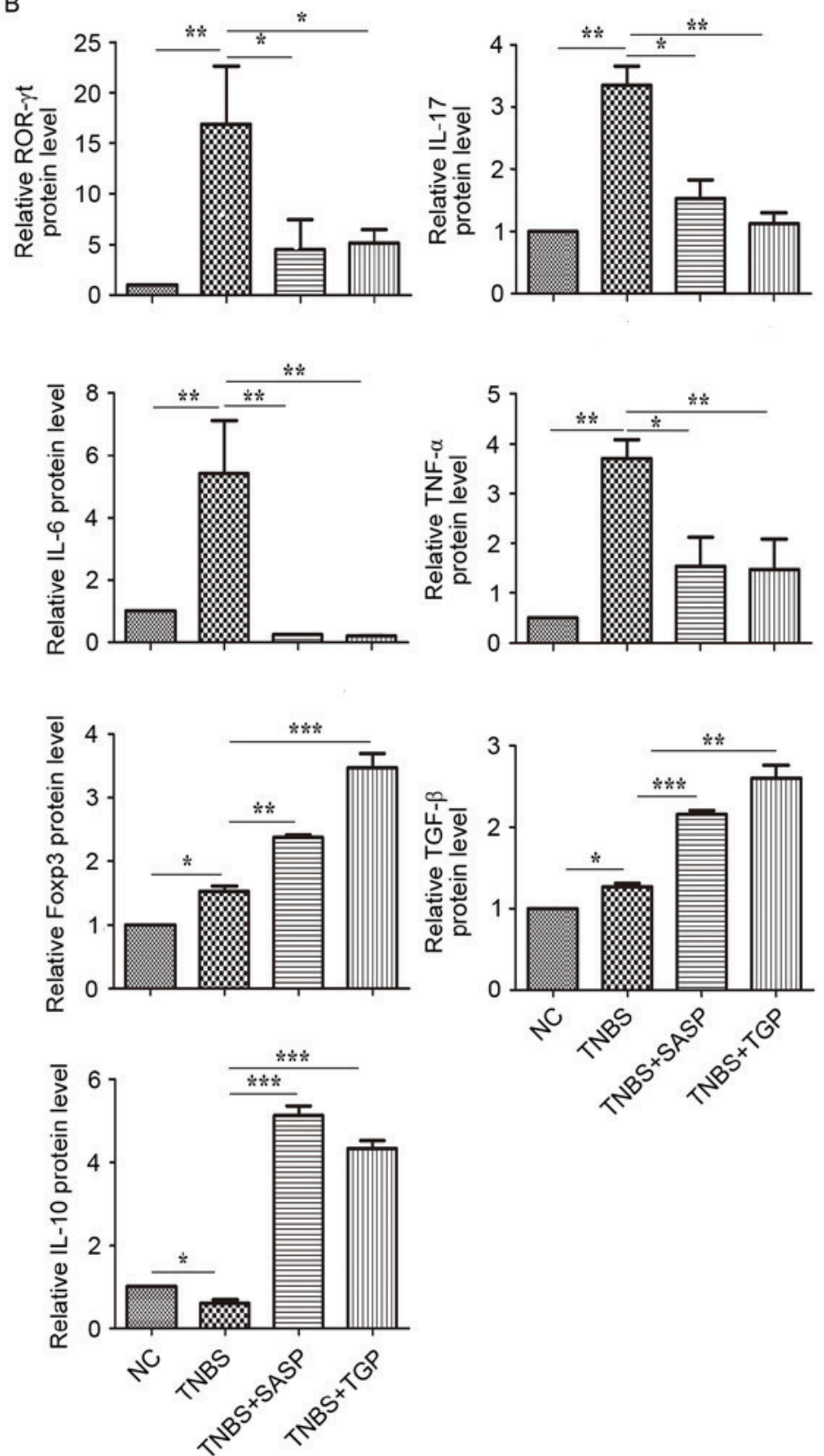

Figure 3. TGP regulates the production of Th17- and Treg-associated cytokines and transcription factors in colonic tissues of TNBS-induced colitis in a similar manner to SASP. (A) Expression of proteins ROR- $\gamma \mathrm{t}$, IL-17, IL-6, TNF- $\alpha$, Foxp3, TNF- $\beta$, IL-10 were determined by western blotting. (B) Data are presented as the mean \pm standard error of the mean. ${ }^{*} \mathrm{P}<0.05,{ }^{* *} \mathrm{P}<0.01,{ }^{* * *} \mathrm{P}<0.001, \mathrm{n} \geq 6$ per group. $\mathrm{NC}$, normal control group; TGP, total glycosides of paeony; SASP, sulfasalazine; Th17, effector $\mathrm{CD}^{+} \mathrm{T}$ helper 17; Treg, regulatory CD4+ $\mathrm{T}$ cells; TNBS, trinitrobenzene sulfonic acid-induced group; TNBS+SASP, TNBS-induced rats treated with SASP; TNBS+TGP, TNBS-induced rats treated with TGP; IL, interleukin; TNF- $\alpha$, tumor necrosis factor- $\alpha$; ROR- $\gamma \mathrm{t}$, retinoic acid related orphan receptor- $\gamma$ t; TNF- $\beta$, transforming growth factor- $\beta$; Foxp3, forkhead boxp3.

for IBD $(44,45)$. Therefore, the present study hypothesized that TGP may differentially contribute to the development of Th17 and Treg cells. In order to determine this, flow cytometry was used to quantify the frequencies of Th17 and Treg cells separated from spleen and MLNs of all groups. As presented in Fig. $9 \mathrm{C}$ and $\mathrm{D}$, the percentage of $\mathrm{CD}^{+}{ }^{+} \mathrm{LL} 17^{+}(\mathrm{Th} 17)$ cells was markedly increased in the TNBS-induced rats, whereas the administration of TGP markedly reduced the percentage, as well as the treatment with SASP. Additionally, the present study revealed that TGP treatment increased the level of $\mathrm{CD}^{+}{ }^{+} \mathrm{CD} 25^{+} \mathrm{Foxp}^{+}$(Treg) cells (Fig. 9A and B). Therefore, these findings indicated that TGP may be able to ameliorate colitis, which was associated with an increased number of Treg cells and a reduction of Th17 cells among spleen and MLNs.

\section{Discussion}

The medical therapeutic strategies for patients with IBD include corticosteroids, biological agents and immunosuppressant drugs. However, efficiency of aforementioned therapies is limited and side effects (including serious infection, myelosuppression and hepatic injury) are too serious to ignore (46). Therefore, more effective and alternative treatments are 
A

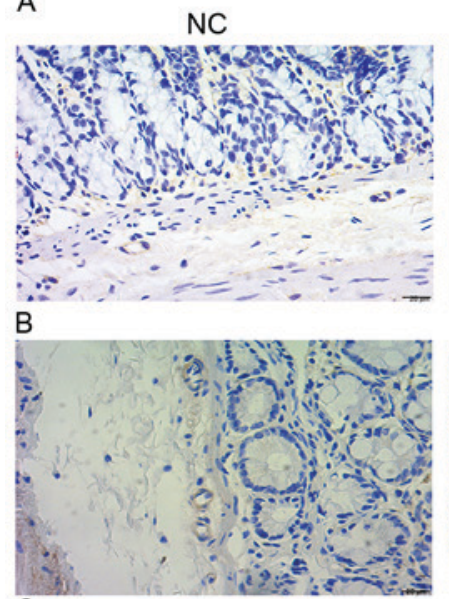

C

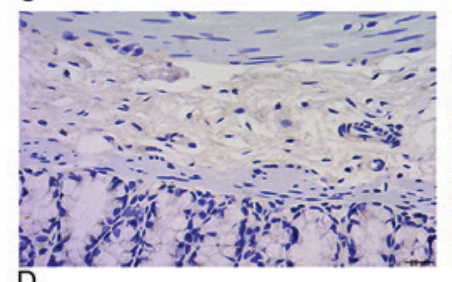

D

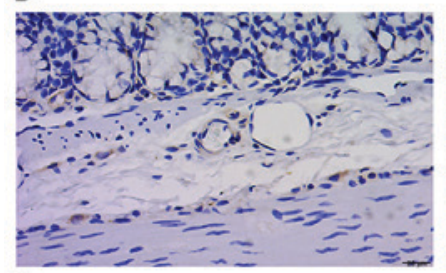

$\mathrm{E}$

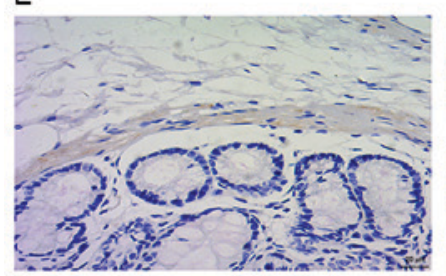

$\mathrm{F}$

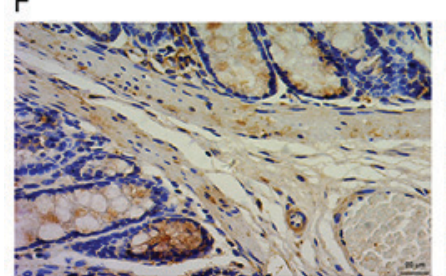

G

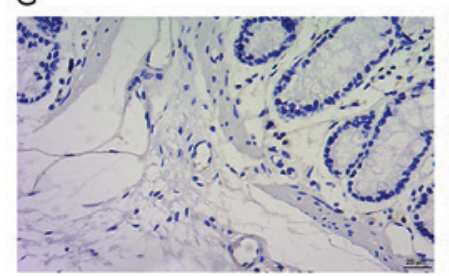

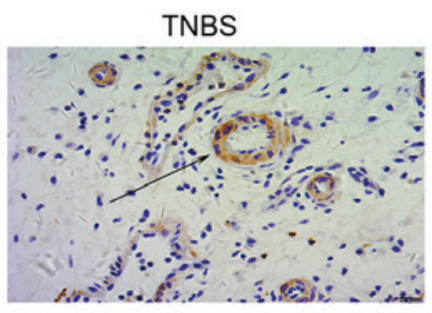
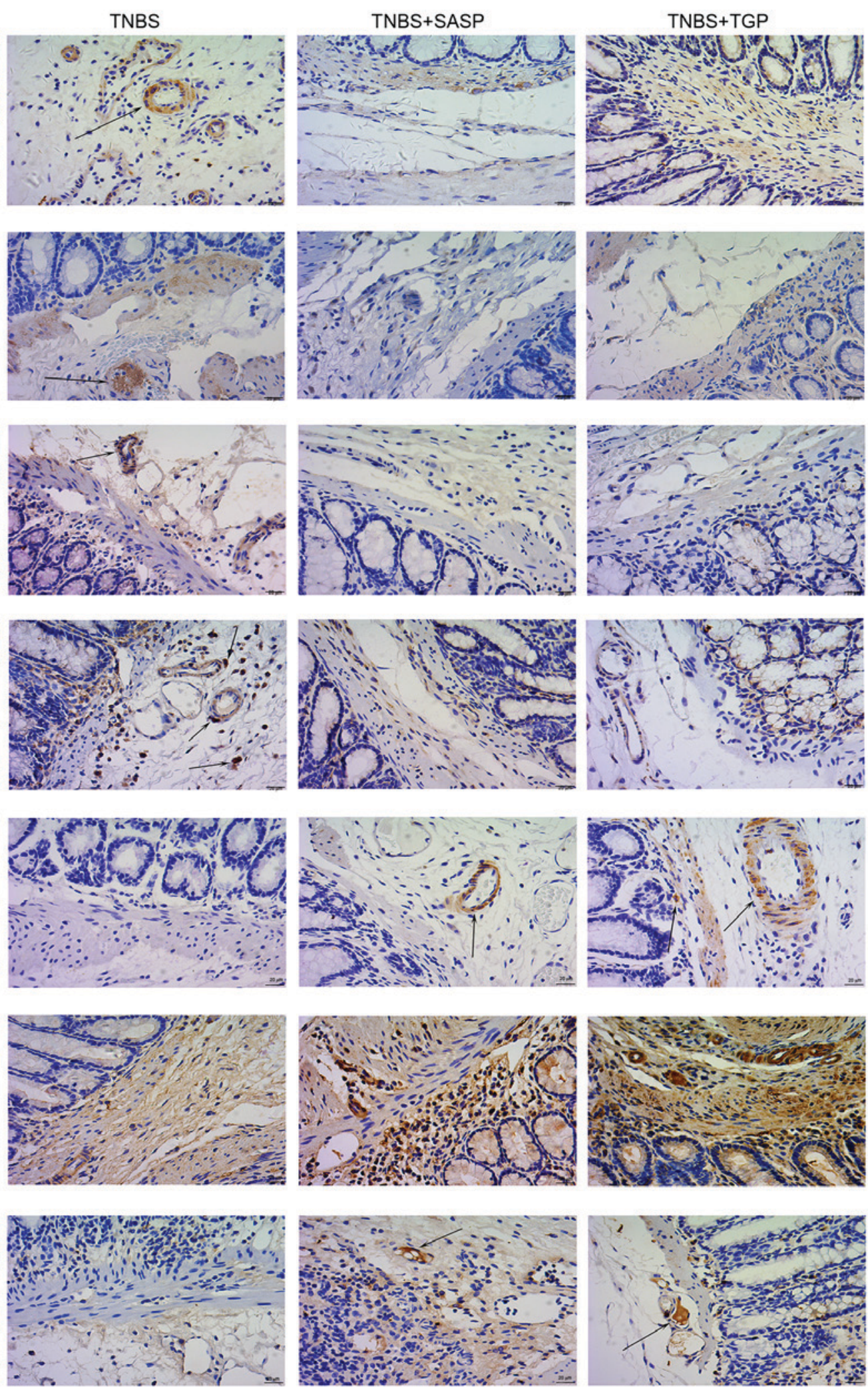

Figure 4. TGP regulates the production of Th17- and Treg-associated cytokines and transcription factors in colonic tissues of TNBS-induced colitis in a similar manner to SASP. Immunohistochemical detection of (A) IL-17, (B) IL-6, (C) TNF- $\alpha$, (D) ROR- $\gamma$, (E) IL-10, (F) TNF- $\beta$, (G) Foxp3 in the colonic tissues. All tissue sections were counterstained with hematoxylin. Magnification, $x 400$. $n \geq 6$ per group. NC, normal control group; TGP, total glycosides of paeony; SASP, sulfasalazine; Th17, effector CD4 ${ }^{+} \mathrm{T}$ helper 17; Treg, regulatory CD4 ${ }^{+} \mathrm{T}$ cells; TNBS, trinitrobenzene sulfonic acid-induced group; TNBS+SASP, TNBS-induced rats treated with TNBS-induced rats treated with SASP; IL, interleukin; TNF- $\alpha$, tumor necrosis factor- $\alpha$; ROR- $\gamma$ t, retinoic acid related orphan receptor- $\gamma \mathrm{t}$; TNF- $\beta$, transforming growth factor- $\beta$; Foxp3, forkhead boxp3.

urgently needed. Although, TGP has been used as a prescription immune-regulatory drug for treating autoimmune diseases including RA, AS and SLE and has exhibited significant effects in the treatment of several animal models, such as experimental 
A

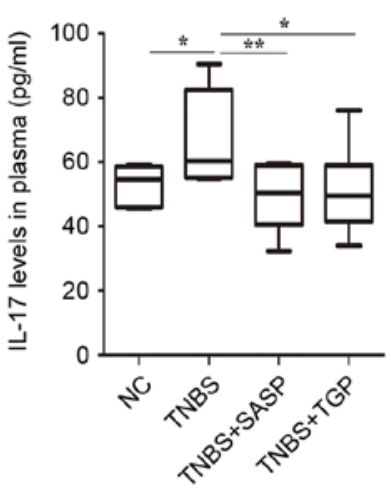

B

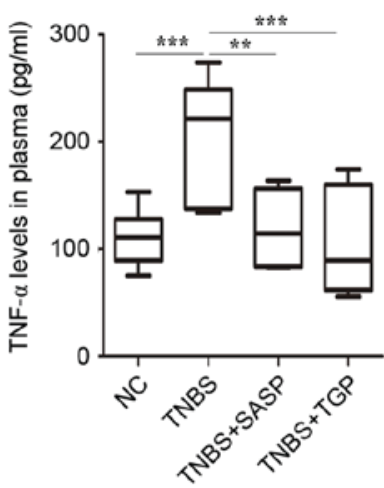

$E$

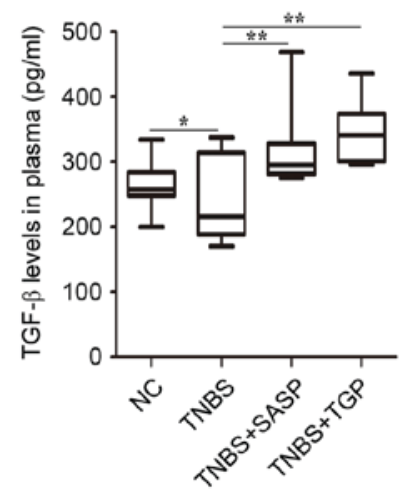

c

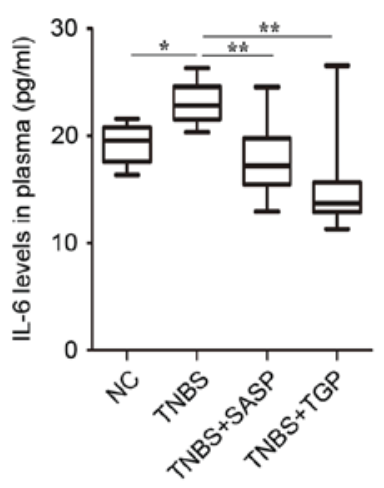

D

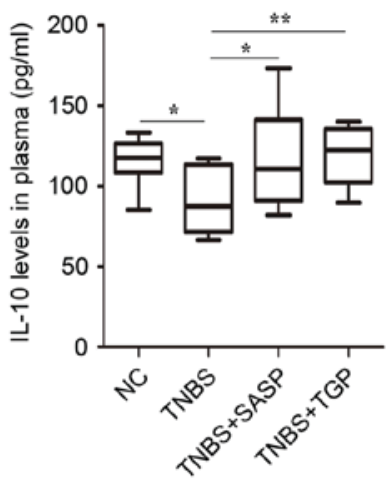

A

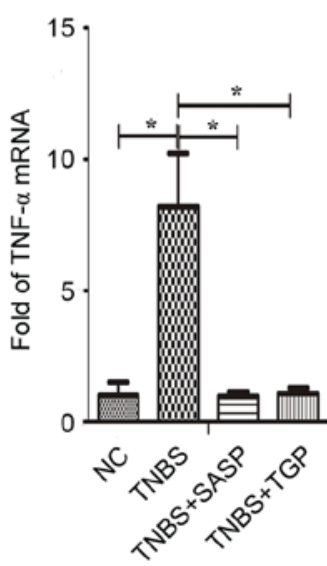

$\mathrm{F}$

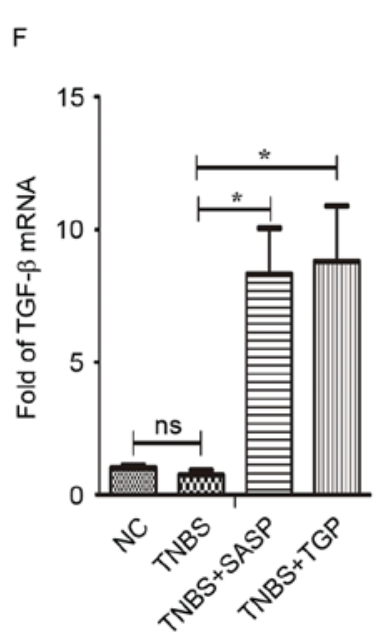

B

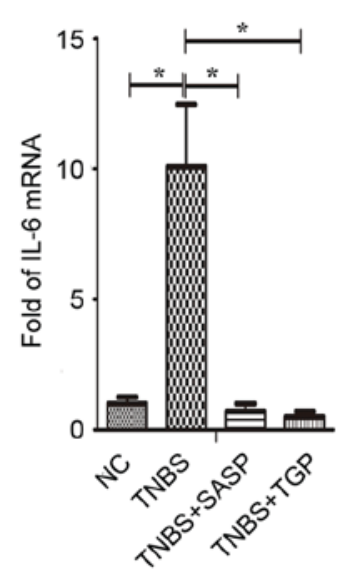

G

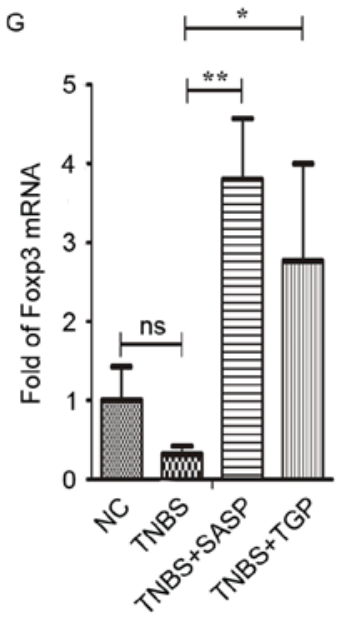

C

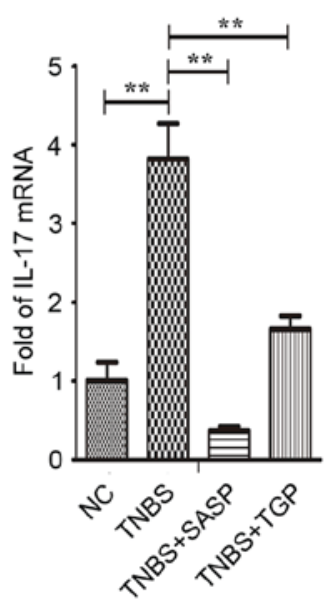

D

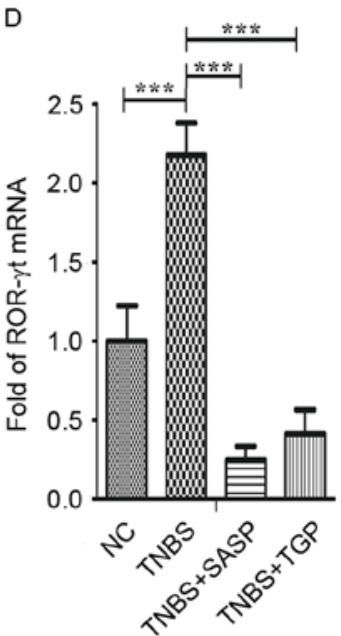

E

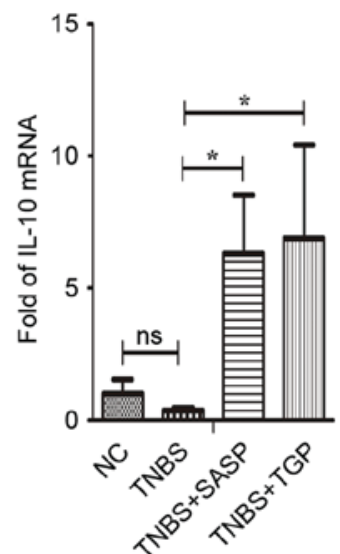

Figure 5. TGP regulates the levels of Th17- and Treg-associated cytokines in plasma in a similar manner to SASP. Effect of drugs treatment on the levels of (A) IL-17, (B) TNF- $\alpha$, (C) IL-6, (D) IL-10, (E) TNF- $\beta$ in plasma are presented. ${ }^{*} \mathrm{P}<0.05,{ }^{* *} \mathrm{P}<0.01,{ }^{* * *} \mathrm{P}<0.001, \mathrm{n} \geq 6$ per group. $\mathrm{NC}$, normal control group; TGP, total glycosides of paeony; SASP, sulfasalazine; Th17, effector $\mathrm{CD}^{+} \mathrm{T}$ helper 17; Treg, regulatory $\mathrm{CD}^{+} \mathrm{T}$ cells; TNBS, trinitrobenzene sulfonic acid-induced group; TNBS+SASP, TNBS-induced rats treated with SASP; TNBS+TGP, TNBS-induced rats treated with TGP; IL, interleukin; TNF- $\alpha$, tumor necrosis factor- $\alpha$; ROR- $\gamma$ t, retinoic acid related orphan receptor- $\gamma \mathrm{t}$; TNF- $\beta$, transforming growth factor- $\beta$; Foxp3, forkhead boxp3.

Figure 6. TGP modulates the mRNA levels of Th17- and Treg-associated cytokines and transcription factors in the colonic tissue of TNBS-induced colitis in a similar manner to SASP. Total mRNA was extracted from colonic tissue to analyze the expression of (A) TNF- $\alpha$, (B) IL-6, (C) IL-17, (D) ROR- $\gamma$ t, (E) IL-10, (F) TNF- $\beta$, (G) Foxp3 by quantitative polymerase chain reaction. ${ }^{*} \mathrm{P}<0.05,{ }^{* *} \mathrm{P}<0.01,{ }^{* * *} \mathrm{P}<0.001, \mathrm{n} \geq 6$ per group. $\mathrm{NC}$, normal control group; TGP, total glycosides of paeony; SASP, sulfasalazine; Th17, effector CD4 ${ }^{+}$ $\mathrm{T}$ helper 17; Treg, regulatory CD4 ${ }^{+} \mathrm{T}$ cells; TNBS, trinitrobenzene sulfonic acid-induced group; TNBS+SASP, TNBS-induced rats treated with SASP; TNBS+TGP, TNBS-induced rats treated with TGP; IL, interleukin; TNF- $\alpha$, tumor necrosis factor- $\alpha$; ROR- $\gamma \mathrm{t}$, retinoic acid related orphan receptor- $\gamma \mathrm{t}$; TNF- $\beta$, transforming growth factor- $\beta$; Foxp3, forkhead boxp3. 
A

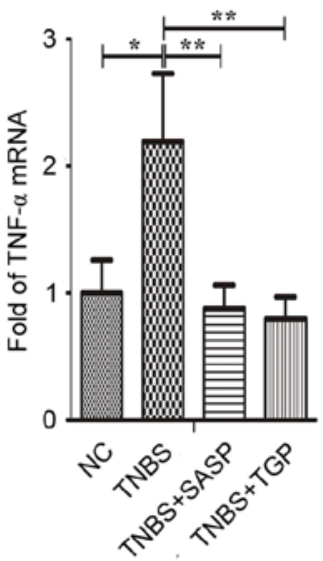

$\mathrm{F}$

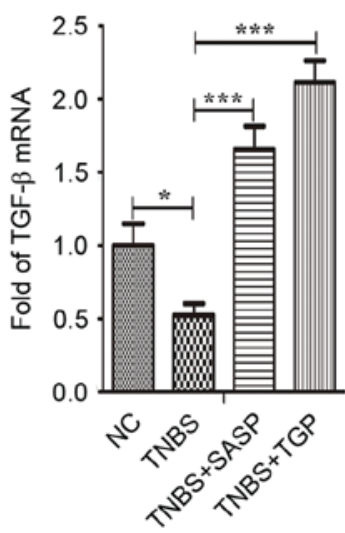

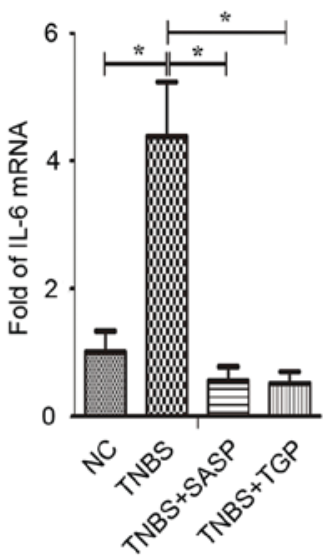

G

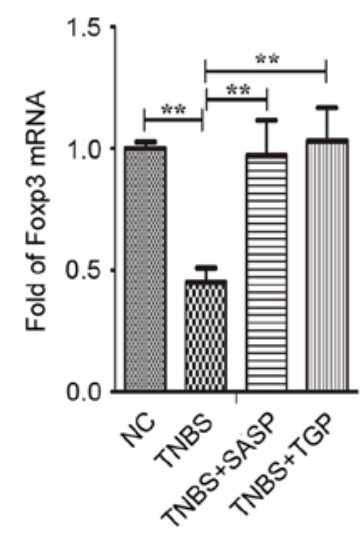

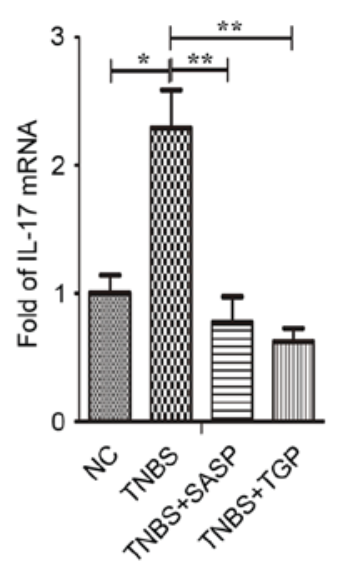

D

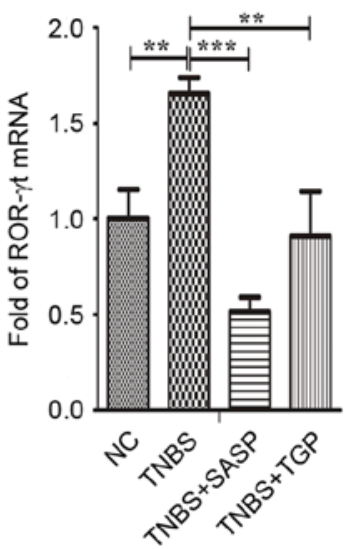

E

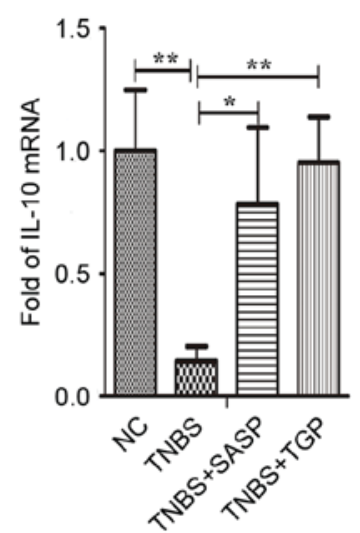

A

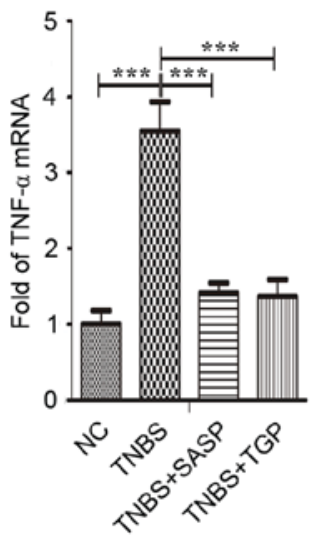

$\mathrm{F}$

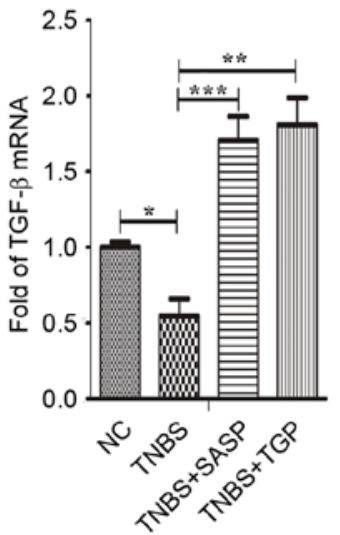

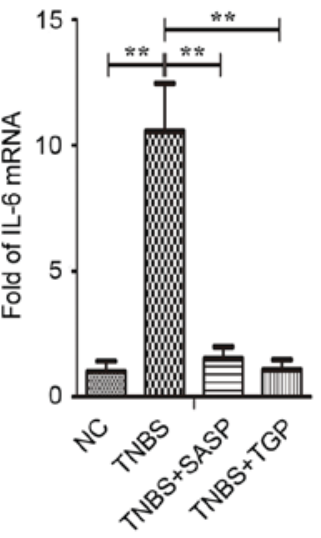

G

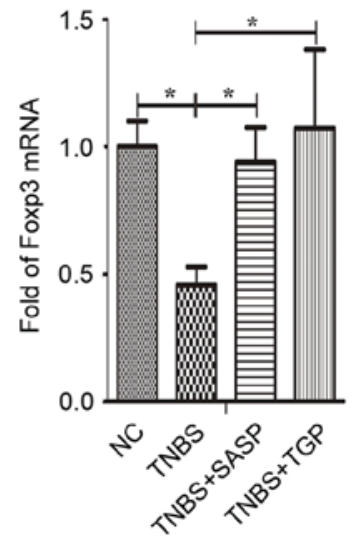

Figure 7. TGP modulates the mRNA levels of Th17- and Treg-associated cytokines and transcription factors in the mesenteric lymph nodes of TNBS-induced colitis in a similar manner to SASP. Total mRNA was extracted from mononuclear cells in the MLN to analyze the expression of (A) TNF- $\alpha$, (B) IL-6, (C) IL-17, (D) ROR- $\gamma$ t, (E) IL-10, (F) TGF- $\beta$, (G) Foxp3 by quantitative polymerase chain reaction. ${ }^{*} \mathrm{P}<0.05,{ }^{* *} \mathrm{P}<0.01,{ }^{* * *} \mathrm{P}<0.001$, $\mathrm{n} \geq 6$ per group. NC, normal control group; TGP, total glycosides of paeony; SASP, sulfasalazine; Th17, effector $\mathrm{CD}^{+}{ }^{+}$Thelper 17; Treg, regulatory CD4 ${ }^{+}$ $\mathrm{T}$ cells; TNBS, trinitrobenzene sulfonic acid-induced group; TNBS+SASP, TNBS-induced rats treated with SASP; TNBS+TGP, TNBS-induced rats treated with TGP; IL, interleukin; TNF- $\alpha$, tumor necrosis factor- $\alpha$; ROR- $\gamma \mathrm{t}$, retinoic acid related orphan receptor- $\gamma$ t; TNF- $\beta$, transforming growth factor- $\beta$; Foxp3, forkhead boxp3.
C

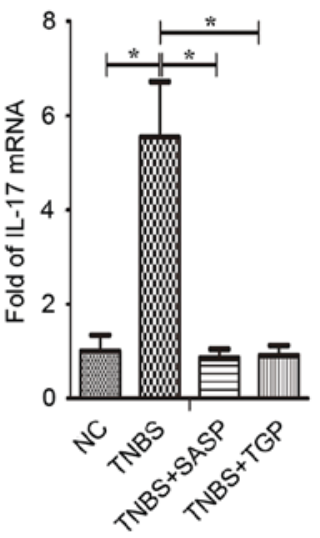

D

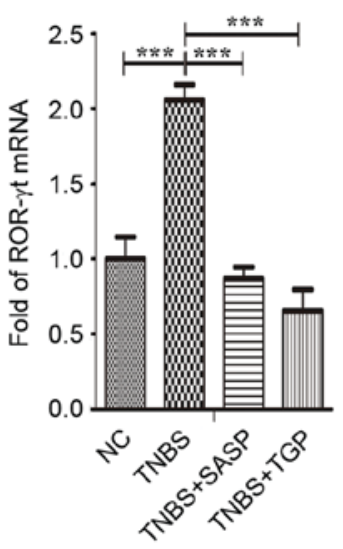

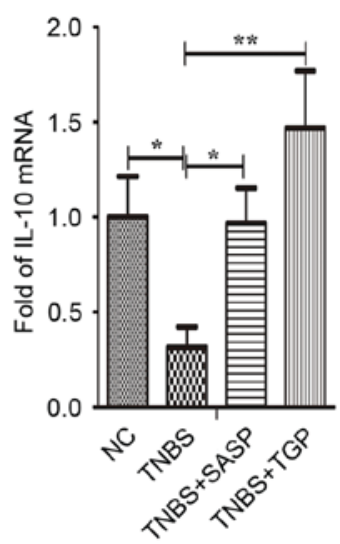

Figure 8. TGP modulates the mRNA levels of Th17- and Treg-associated cytokines and transcription factors in the spleen of TNBS-induced colitis in a similar manner to SASP. Total mRNA was extracted from mononuclear cells in the spleen to analyze the expression of (A) TNF- $\alpha$, (B) IL-6, (C) IL-17, (D) ROR- $\gamma$ t, (E) IL-10, (F) TNF- $\beta$, (G) Foxp3 by quantitative polymerase chain reaction. ${ }^{*} \mathrm{P}<0.05,{ }^{* *} \mathrm{P}<0.01,{ }^{* * * *} \mathrm{P}<0.001, \mathrm{n} \geq 6$ per group. $\mathrm{NC}$, normal control group; TGP, total glycosides of paeony; SASP, sulfasalazine; Th17, effector $\mathrm{CD}^{+}{ }^{+} \mathrm{T}$ helper 17; Treg, regulatory $\mathrm{CD} 4^{+} \mathrm{T}$ cells; TNBS, trinitrobenzene sulfonic acid-induced group; TNBS+SASP, TNBS-induced rats treated with SASP; TNBS+TGP, TNBS-induced rats treated with TGP; IL, interleukin; TNF- $\alpha$, tumor necrosis factor- $\alpha$; ROR- $\gamma$ t, retinoic acid related orphan receptor- $\gamma \mathrm{t}$; TNF- $\beta$, transforming growth factor- $\beta$; Foxp3, forkhead boxp3. 
A

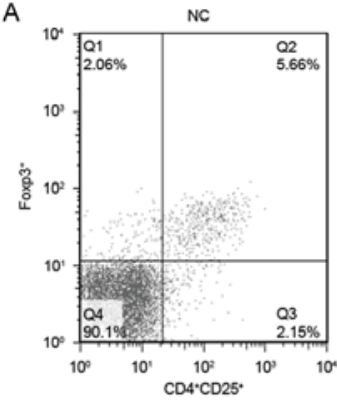

B

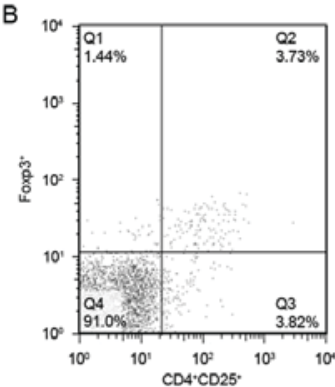

C

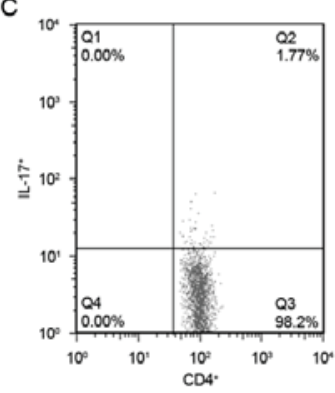

D

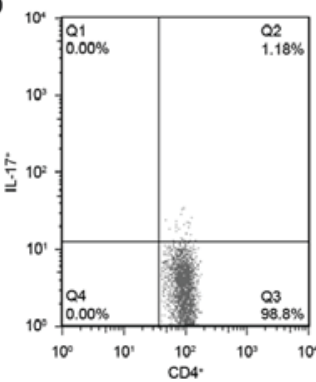

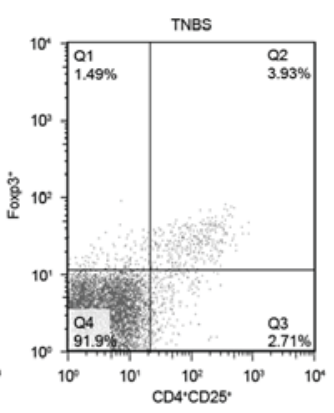
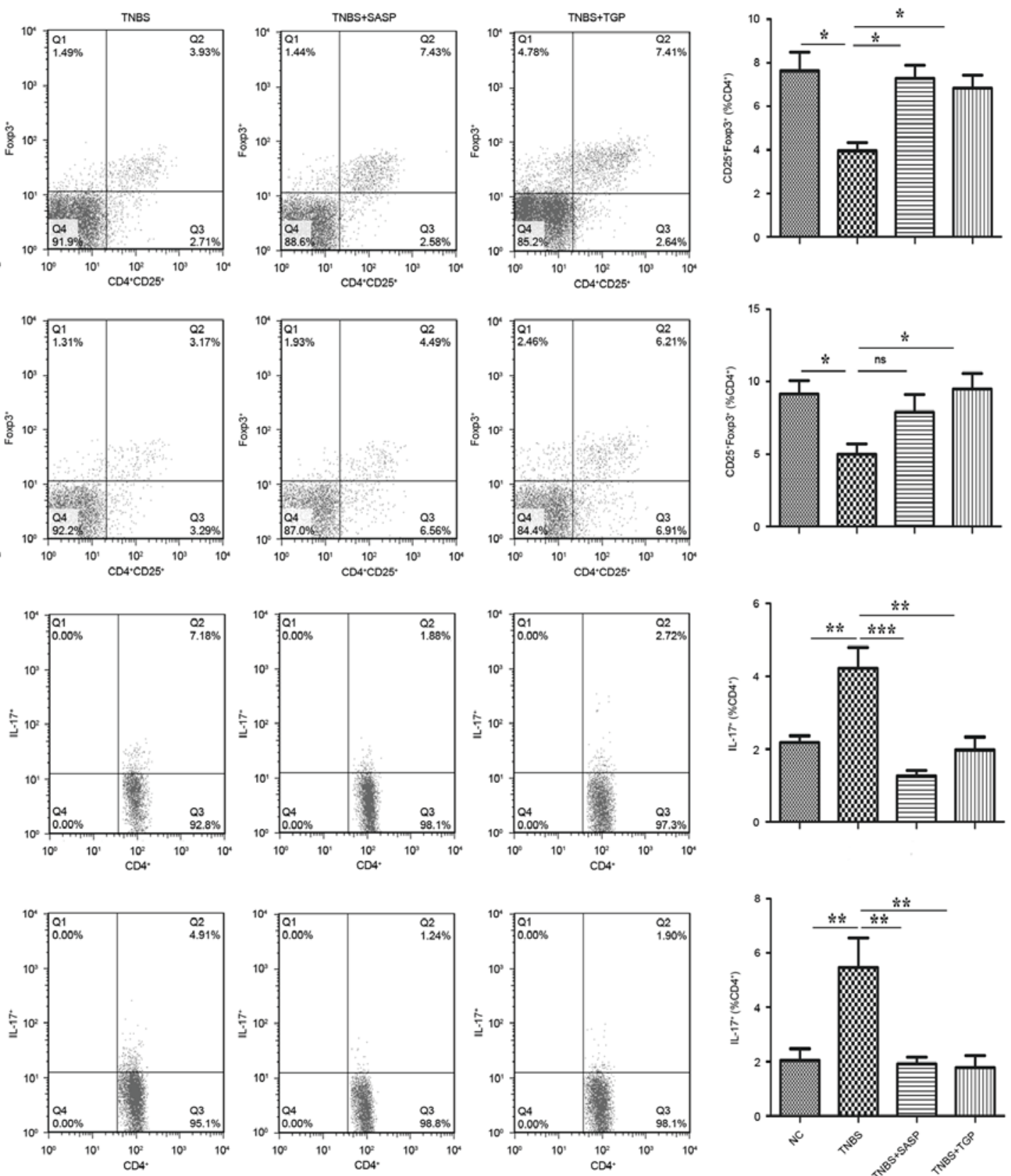

Figure 9. TGP regulates frequencies of Th17 and Treg cells in the TNBS-induced colitis in a similar manner to SASP. Mononuclear cells of spleen and MLN were isolated from each group and subjected to intracellular IL-17 and Foxp3 staining. The frequency of Treg (CD4 $\left.{ }^{+} \mathrm{CD} 25^{+} \mathrm{Foxp} 3^{+}\right)$in the (A) MLN and (B) spleen and Th17 (CD4+IL-17+) in the (C) MLN and (D) spleen were determined by flow cytometry. Quantitative analysis of the frequency was performed simultaneously. NC, normal control group; TGP, total glycosides of paeony; SASP, sulfasalazine; Th17, effector CD4 ${ }^{+}$T helper 17; Treg, regulatory CD4 ${ }^{+}$ T cells; TNBS, trinitrobenzene sulfonic acid-induced group; TNBS+SASP, TNBS-induced rats treated with SASP; TNBS+TGP, TNBS-induced rats treated with TGP; IL-17, interleukin-17; Foxp3, forkhead boxp3; MLN, mesenteric lymph nodes.

autoimmune encephalomyelitis, collagen induced arthritis and TNBS-induced colitis $(26,30,33,36)$, it remains to be elucidated how TGP exerts its therapeutic effects.

Previous studies have revealed that the potential mechanism of TGP in TNBS-induced colitis may be associated with the adjustment of Th1/Th2 cytokine polarization $(37,47)$. However, TGP has also been reported to impair Th17 differentiation by reducing the production of IL-6 and increase the proportion of Treg cells $(30,34)$. Additionally, perturbation in the balance between Th17 and Treg cells may lead to aberrant inflammation responses having a role in IBD (2). Therefore, the present study investigated the role for TGP in attenuating TNBS-induced colitis via regulation of the Th17/Treg balance.

Following previous studies $(38,48)$, the present study selected the well-established model of TNBS-induced experimental colitis to evaluate the effect of TGP, which is characterized by intense weight loss, diarrhea, bleeding, colonic injury and invasion of inflammatory cells infiltration. In the present study, TGP-treated rats had attenuated weight loss, clinical signs and a reduction in histological markers of inflammation.

Additionally, the present study demonstrated that TGP significantly reduced levels of Th17-associated cytokines 
(IL-17) and TNF- $\alpha$, whereas increased levels of Treg-associated cytokines (TNF- $\beta$ and IL-10) were observed in the colon. Similar to colonic tissue, a decreased secretion of IL-17 and TNF- $\alpha$ and increased secretion of TNF- $\beta$ and IL-10 was observed in peripheral blood, MLNs and spleen. The changes of TNF- $\alpha$ and IL-10 were in line with a previous study (37). It is evident that the inappropriate production of IL-17 contributes to the pathology of IBD and the anti-inflammatory cytokines IL-10 and TNF- $\beta$ may prevent the established colitis in animal models of IBD $(6,9,12)$. These data indicated that TGP was able to shift the pro-inflammatory environment to anti-inflammatory status leading to ameliorate colitis. Previous studies have highlighted that IBD is associated with imbalance between Th17 and Treg cells and TNF- $\beta$ drives the differentiation of Treg cells, whereas Th17 cells are induced by a combination of IL- 6 and TNF- $\beta(1,9,21,24,49)$. Therefore, TNF- $\beta$ is an effector molecule of Treg cells and has a dual role in the differentiation of Th17 and Treg cells. TNF- $\beta$ promotes the production of Treg by inducing Foxp3 expression. However, in the presence of IL-6, it induces the expression of ROR- $\gamma$ t and IL-23R to promote the Th17 phenotype (19). In the TGP-treated TNBS-induced rat group, the present study identified downregulation of IL-6 and upregulation of TNF- $\beta$ in the colon, plasma, MLNs and spleen. Concordant with these results, the present study revealed that TGP treatment significantly reduced percentages of Th17 cells and increased percentages of Treg cells in the MLNs and spleen of TNBS-induced rats. Overall, these data supported the hypothesis that TGP-regulated Th17 and Treg subset differentiation to control inflammation of experimental colitis. Additionally, transcription factors have a crucial role in T-cell differentiation; therefore, the present study tested lineage-specific transcriptional regulators ROR- $\gamma$ t and Foxp3. ROR- $\gamma$ t dominated Th17 differentiation and favored the occurrence of immune response by producing IL-17 cytokines (50). Foxp3 directed Treg formation and confer their regulatory activity by production of TNF- $\beta$ and IL-10 cytokines $(15,51)$. Therefore, the marked reduction of ROR- $\gamma \mathrm{t}$ mRNA and protein levels and the increased Foxp3 expression in the colon, MLNs and spleen were regarded as another mechanism that TGP contributed towards establishing the homeostasis of Th17 and Treg cells in the response to TNBS-induced damage.

SASP is a commonly prescribed drug with proven efficacy in the treatment of IBD (52). The present study compared the effects of TGP and SASP in experimental colitis. Subsequently, treatment with TGP daily resulted in a therapeutic effect equal to that of SASP.

In summary, the present study indicated that TGP may improve symptoms of TNBS-induced colitis by regulating cytokine production, inhibiting effector phenotype of Th17 cells and facilitating Treg responses. These anti-inflammatory properties of TGP may offer an opportunity to use it as a novel candidate for the treatment of IBD. However, further mechanism studies are required to prove its immunomodulatory effect in other models of colitis.

\section{Acknowledgements}

The present study was supported by the Public Technology Research Project of Zhejiang Province (grant no. 2015C33120) and the Natural Science Foundation of China (grant no. 81570495).

\section{References}

1. Cătană CS, Berindan Neagoe I, Cozma V, Magdaş C, Tăbăran F and Dumitrascu DL: Contribution of the IL-17/IL-23 axis to the pathogenesis of inflammatory bowel disease. World J Gastroenterol 21: 5823-5830, 2015.

2. Geremia A, Biancheri P, Allan P, Corazza GR and Di Sabatino A: Innate and adaptive immunity in inflammatory bowel disease. Autoimmun Rev 13: 3-10, 2014.

3. Glauben R, Batra A, Stroh T, Erben U, Fedke I, Lehr HA, Leoni F, Mascagni P, Dinarello CA, Zeitz M and Siegmund B: Histone deacetylases: Novel targets for prevention of colitis-associated cancer in mice. Gut 57: 613-622, 2008.

4. Salim SY and Söderholm JD: Importance of disrupted intestinal barrier in inflammatory bowel diseases. Inflamm Bowel Dis 17: 362-381, 2011.

5. Veltkamp C,Anstaett M, Wahl K, Möller S, Gangl S, Bachmann O, Hardtke-Wolenski M, Länger F, Stremmel W, Manns MP, et al: Apoptosis of regulatory $\mathrm{T}$ lymphocytes is increased in chronic inflammatory bowel disease and reversed by anti-TNF $\alpha$ treatment. Gut 60: 1345-1353, 2011.

6. Maul J, Loddenkemper C, Mundt P, Berg E, Giese T, Stallmach A Zeitz $M$ and Duchmann R: Peripheral and intestinal regulatory $\mathrm{CD} 4^{+} \mathrm{CD} 25$ (high) $\mathrm{T}$ cells in inflammatory bowel disease. Gastroenterology 128: 1868-1878, 2005.

7. Brand S: Crohn's disease: Th1, Th17 or both? The change of a paradigm: New immunological and genetic insights implicate Th17 cells in the pathogenesis of Crohn's disease. Gut 58: 1152-1167, 2009.

8. Kaser A, Zeissig S and Blumberg RS: Inflammatory bowel disease. Annu Rev Immunol 28: 573-621, 2010.

9. Eastaff-Leung N, Mabarrack N, Barbour A, Cummins A and Barry S: Foxp $3^{+}$regulatory $\mathrm{T}$ cells, Th17 effector cells, and cytokine environment in inflammatory bowel disease. J Clin Immunol 30: 80-89, 2010.

10. Gaffen SL: An overview of IL-17 function and signaling. Cytokine 43: 402-407, 2008.

11. Dambacher J, Beigel F, Zitzmann K, De Toni EN, Göke B, Diepolder HM, Auernhammer CJ and Brand S: The role of the novel Th17 cytokine IL-26 in intestinal inflammation. Gut 58: 1207-1217, 2009.

12. Fujino S, Andoh A, Bamba S, Ogawa A, Hata K, Araki Y, Bamba T and Fujiyama Y: Increased expression of interleukin 17 in inflammatory bowel disease. Gut 52: 65-70, 2003.

13. Nielsen $\mathrm{OH}$, Kirman I, Rüdiger N, Hendel $\mathrm{J}$ and Vainer B: Upregulation of interleukin-12 and -17 in active inflammatory bowel disease. Scand J Gastroenterol 38: 180-185, 2003.

14. Valencia X, Stephens G, Goldbach-Mansky R, Wilson M, Shevach EM and Lipsky PE: TNF downmodulates the function of human $C D 4^{+} C D 25^{\text {hi }}$ T-regulatory cells. Blood 108: 253-261, 2006.

15. Hori S, Nomura T and Sakaguchi S: Control of regulatory T cell development by the transcription factor Foxp3. Science 299: 1057-1061, 2003.

16. O'Garra A and Vieira P: Regulatory T cells and mechanisms of immune system control. Nat Med 10: 801-805, 2004

17. Singh B, Read S, Asseman C, Malmstrom V, Mottet C, Stephens LA, Stepankova R, Tlaskalova H and Powrie F: Control of intestinal inflammation by regulatory T cells. Immunol Rev 182: 190-200, 2001.

18. Mottet C, Uhlig HH and Powrie F: Cutting edge: Cure of colitis by $\mathrm{CD} 4{ }^{+} \mathrm{CD} 25^{+}$regulatory T cells. J Immunol 170: 3939-3943, 2003.

19. Galvez J: Role of Th17 cells in the pathogenesis of Human IBD. ISRN Inflamm 2014: 928461, 2014.

20. Hansen R, Thomson JM, El-Omar EM and Hold GL: The role of infection in the aetiology of inflammatory bowel disease. J Gastroenterol 45: 266-276, 2010.

21. Bettelli E, Carrier Y, Gao W, Korn T, Strom TB, Oukka M, Weiner HL and Kuchroo VK: Reciprocal developmental pathways for the generation of pathogenic effector TH17 and regulatory T cells. Nature 441: 235-238, 2006

22. Mangan PR, Harrington LE, O'Quinn DB, Helms WS, Bullard DC, Elson CO, Hatton RD, Wahl SM, Schoeb TR and Weaver CT: Transforming growth factor-beta induces development of the T(H)17 lineage. Nature 441: 231-234, 2006. 
23. Zhu J and Paul WE: Heterogeneity and plasticity of T helper cells. Cell Res 20: 4-12, 2010.

24. Veldhoen M, Hocking RJ, Atkins CJ, Locksley RM and Stockinger B: TGFbeta in the context of an inflammatory cytokine milieu supports de novo differentiation of IL-17-producing T cells. Immunity 24: 179-189, 2006.

25. Wu CF: A review on the pharmacology of Paeonia lactiflora and its chemical components. Zhong Yao Tong Bao 10: 43-45, 1985 (In Chinese)

26. Zhang LL, Wei W, Wang NP, Wang QT, Chen JY, Chen Y, $\mathrm{Wu} \mathrm{H}$ and $\mathrm{Hu} \mathrm{XY}$ : Paeoniflorin suppresses inflammatory mediator production and regulates $\mathrm{G}$ protein-coupled signaling in fibroblast-like synoviocytes of collagen induced arthritic rats. Inflamm Res 57: 388-395, 2008

27. He DY and Dai SM: Anti-inflammatory and immunomodulatory effects of Paeonia lactiflora Pall., a traditional chinese herbal medicine. Front Pharmacol 2: 10, 2011.

28. Lee B, Shin YW, Bae EA, Han SJ, Kim JS, Kang SS and Kim DH: Antiallergic effect of the root of Paeonia lactiflora and its constituents paeoniflorin and paeonol. Arch Pharm Res 31: 445-450, 2008

29. Kim ID and Ha BJ: The effects of paeoniflorin on LPS-induced liver inflammatory reactions. Arch Pharm Res 33: 959-966, 2010.

30. Lin J, Xiao L, Ouyang G, Shen Y, Huo R, Zhou Z, Sun Y, Zhu X, Zhang J, Shen B and Li N: Total glucosides of paeony inhibits Th1/Th17 cells via decreasing dendritic cells activation in rheumatoid arthritis. Cell Immunol 280: 156-163, 2012.

31. Zhu L, Wei W, Zheng YQ and Jia XY: Effects and mechanisms of total glucosides of paeony on joint damage in rat collagen-induced arthritis. Inflamm Res 54: 211-220, 2005.

32. Wu Y, Ren K, Liang C, Yuan L, Qi X, Dong J, Shen J and Lin S: Renoprotective effect of total glucosides of paeony (TGP) and its mechanism in experimental diabetes. J Pharmacol Sci 109: 78-87, 2009.

33. Huang Q, Ma X, Zhu DL, Chen L, Jiang Y, Zhou L, Cen L, Pi R and Chen X: Total glucosides of peony attenuates experimental autoimmune encephalomyelitis in C57BL/6 mice. J Neuroimmunol 284: $67-73,2015$.

34. Zhao M, Liang GP, Tang MN, Luo SY, Zhang J, Cheng WJ, Chan TM and Lu QJ: Total glucosides of paeony induces regulatory CD4(+)CD25(+) T cells by increasing Foxp3 demethylation in lupus CD4(+) T cells. Clin Immunol 143: 180-187, 2012

35. Cao W, Zhang W, Liu J, Wang Y, Peng X, Lu D, Qi R, Wang Y and Wang H: Paeoniflorin improves survival in LPS-challenged mice through the suppression of TNF- $\alpha$ and IL-1 $\beta$ release and augmentation of IL-10 production. Int Immunopharmacol 11: 172-178, 2011.

36. Liu GL, Li YC and Shen YJ: Inhibitory effect of total glucosides of paeonia on the NF- $\mathrm{kB} / \mathrm{p} 65$ protein expression in paws of RA rats. Xi Bao Yu Fen Zi Mian Yi Xue Za Zhi 26: 1082-1084, 2010 (In Chinese).
37. Zhang Y, Zhou R, Zhou F, Cheng $\mathrm{H}$ and Xia B: Total glucosides of peony attenuates 2,4,6-trinitrobenzene sulfonic acid/ ethanol-induced colitis in rats through adjustment of TH1/TH2 cytokines polarization. Cell Biochem Biophys 68: 83-95, 2014.

38. Wirtz S, Neufert C, Weigmann B and Neurath MF: Chemically induced mouse models of intestinal inflammation. Nat Protoc 2: 541-546, 2007.

39. Alex P,Zachos NC, Nguyen T, Gonzales L, Chen TE, Conklin LS, Centola M and Li X: Distinct cytokine patterns identified from multiplex profiles of murine DSS and TNBS-induced colitis. Inflamm Bowel Dis 15: 341-352, 2009.

40. Zou Y, Li WY, Wan Z, Zhao B, He ZW, Wu ZG, Huang GL, Wang J, Li BB, Lu YJ, et al: Huangqin-Tang ameliorates TNBS-induced colitis by regulating effector and regulatory CD4(+) T cells. Biomed Res Int 2015: 102021, 2015.

41. Bell CJ, Gall DG and Wallace JL: Disruption of colonic electrolyte transport in experimental colitis. Am J Physiol 268 G622-G630, 1995.

42. Scheiffele F and Fuss IJ: Induction of TNBS colitis in mice. Curr Protoc Immunol Chapter 15: Unit 15, 2002.

43. Livak KJ and Schmittgen TD: Analysis of relative gene expression data using real-time quantitative PCR and the 2(-Delta Delta C(T)) method. Methods 25: 402-408, 2001.

44. Himmel ME, Yao Y, Orban PC, Steiner TS and Levings MK: Regulatory T-cell therapy for inflammatory bowel disease: More questions than answers. Immunology 136: 115-122, 2012.

45. Xavier RJ and Podolsky DK: Unravelling the pathogenesis of inflammatory bowel disease. Nature 448: 427-434, 2007.

46. Baumgart DC and Sandborn WJ: Inflammatory bowel disease: Clinical aspects and established and evolving therapies. Lancet 369: 1641-1657, 2007.

47. Strober W, Fuss IJ and Blumberg RS: The immunology of mucosal models of inflammation. Annu Rev Immunol 20: 495-549, 2002

48. Zhou L, Ivanov II, Spolski R, Min R, Shenderov K, Egawa T, Levy DE, Leonard WJ and Littman DR: IL-6 programs T(H)-17 cell differentiation by promoting sequential engagement of the IL-21 and IL-23 pathways. Nat Immunol 8: 967-974, 2007.

49. Ivanov II, McKenzie BS, Zhou L, Tadokoro CE, Lepelley A, Lafaille JJ, Cua DJ and Littman DR: The orphan nuclear receptor RORgammat directs the differentiation program of proinflammatory IL-17+ ${ }^{+}$helper cells. Cell 126: 1121-1133, 2006.

50. Fontenot JD, Gavin MA and Rudensky AY: Foxp3 programs the development and function of $\mathrm{CD} 4{ }^{+} \mathrm{CD} 25^{+}$regulatory $\mathrm{T}$ cells. Nat Immunol 4: 330-336, 2003.

51. Tamboli CP: Current medical therapy for chronic inflammatory bowel diseases. Surg Clin North Am 87: 697-725, 2007.

52. Zhou J, Wu ZX, Yang JH, et al: Effect of total glucosides of Paeony on TNBS-in duced experimental Colitis in rats. Chin J Gastroenterol 4: 154-158, 2009. 